\title{
VERDADES CLINICAS
}

A medicina assenta, entes de tudo, na observação: é o que os antigos, na sua linguagem axiomatica, já preceituavam no "ars tota in observationibus", conceito que, nem por muito sediço e repisado, deve ser olvidado, mórmente ao nos dirigirmos aos moços, quando elle merece revivido e relembrado.

Da observação accumulada dos factos se constituiu e se vae constituindo a medicina, como dessa mesma observação, através đos annos, se forma o espirito clinico. O bom clinico necessita, a par de excellentes e bem apuradas faculdades de observação, de um sem numero de concepções theoricas, que lhe permittam a interpretação e a estimativa dos phenomenos morbidos. Não deve, porém, sacrificar uma pela outra: aqui, como em tudo o mais, a virtude reside no meio termo. O excesso de erudição, quando mal applicado, es ţão condemnavel e pernicioso quanto o espirito pratico levado ao exaggero. Cumpre ao clinico, àe pesse dos dados doutrinarios e theoricos, verifical-os e comproval-os na pretica, passal-os pelo cadinho da experiencia, modificando-os e ampliando-os consoante lh'o ditar a obserração. Factos ha que são moeda corrente nos livros, mas que a pratica não sancciona: ha outros, de verificação diaria, e que a theoria não menciona. São, comtudo, verdades clinicas. A syphilis, tođo o mundo sabe-o de sobejo, é, senão o maior, pelo menos um dos maiores flagellos da humanidade.

Bem feitas as contas, devidamente apurados os seus effeitos proximos e remotos e avaliados, com rigor, os seus maleficios, chega-se á conclusão de que não ha mclestia que a sobrepuje nos seus coefficientes de morbilidade e letalidade, $n \in m$ mesmo a tuberculose. Uma boa parte da pathologia lhe pertence de direito. Por jsso, talvez assista razão a proficiente medico patricio, quando sentenciou que, em clinica, deve pensar-se syphiliticamente.

A medicina interna incide, directamente, sob o seu raio de acção, de modo que aos chamados syphilographos ficam reservadas, exclusivamente, as determinações cutaneas do mal.

Nem sempre, entretanto, o espirito clinico joeira, com verdade e justiça, o campo da syphilis: rouba-lhe, por vezes, o que de facto lhe pertence e dá-lhe aquillo que, na realidade, cabe a outros. 0 caso dos aneurysmas aorticos e o das ulceras pepticas são bem fr1santes a esse respeito e exemplificam, cabalmente, as duas condições. 
Se se compulsam os livros de pathologia e de clinica, mesmo os mais modernos, deparam-se-nos, infallivelmente, enumeradas varias causas de aneurysmas da aorta. Todos os autores, nenime discrepante, assignalam, é bem verdade, o papel preponderante da syphilis na producção desses aneurysmas, mas, ao lado della, ainda se lê, enfileirada, a série longa de causas outras, tambem passiveis de exercer a mesma acção pathogenica.

Nos tempos idos, quando a comprovação da lues nem sempre era facil, comprehende-se que assim fosse e que se prégasse, como de facto se prégava, que causas outras, que não a syphilis, pudessem determinar taes arteriopathias. Nos dias que correm, porém, em que a demonstração da syphilis, na sua triplice determinação - clinica, biologica e anatomica - é facto correntio, não existem motivos razoaveis para que se persista no erro e não se firme, com todas as prerogativas de um dogma, o monopolio etiologico da syphilis em relação aos aneurysmas aorticos. Outr'ora, quando a syphilis fugia aos nossos meios de pesquisa, era natural que se alongasse ao infinito a lista dos agentes causaes daquellas molestia: actualmente, com os processos de que dispomos, não ha como se não possa rastrear a lues em qualquer caso. Alguem ha, porventura, que se abalance a lembrar, para a tabes dorsal, de outra etiologia que não seja a luetica? Por certo que não. O facto passou em julgado, corroborou-o a experimentação, e, diagnosticada a tabes, está, implicitamente, diagnosticada a sua causa.

Quem diz tabes, diz syphilis, ou, equacionalmente, tabes $=$ syphilis.

Porque se não ha de proceder do mesmo modo em relação aos aneurysmas aorticos?

E' o primeiro exemplo, esse que ahi fica, da actuação restrictiva, que se quer impôr á syphilis, cerceando-lhe a exclusividade, qưo ella incontestavelmente tem, no apparecimento desses aneurysmas.

Vejamos a outra face do problema: atira-se á conta da syphilis muito mal que ella, nem directa e nem indirectametne, asarreta. Já se escreveu algures que a syphilis é um excellente rotulo: estado morbido que não tenha causa facilmente apprehensivel, ella ahi está, sempre á mão, como a grande fabricadora de molestias, um vistoso rotulo a ser apposto para salvação de tudo. menos do toente. Isto que se passa com a syphilis, já se passou, em menor grau, com outras molestias: tempo houve em que a hysteria tudo simulava, e, não ha muito, as prelecções sobre o impaludismo começavam, indefectivelmente, proclamando-o o grande proteu, sob cuja responsabilidade se collocava quasi toda a pathologia.

As ulceras pepticas, que se assestam, como é do conhecimento geral, em determinado trecho do tubo digestivo, sobre serem grandemente frequentes em clinica, ainda não tiveram, no que concerne 
á respectiva etio-pathogenia, os devidos e precisos esclarecimentos. Conhecem-se-lhes a symptcmatologia, a evoluçâo, as complicações, do mesmo modo por que muito se têm avançado de referencia á sua therapeutica: as suas causas, porém, essas ainda nos escapam totalmente, de sorte que esse vem a ser um dos mais obscuros capitulos da pathologia e clinica digestivas.

Tudo, nesse dominio, são puras e meras hypotheses, cada qual melhor architectada e melhor apadrinhada.

Aqui, apregoa-se ser o succo gastrico, segregado em excesso, $\theta$ hyperacido, o agente corrosivo das paredes do estomago, que se ulceram, não se explicando, entretanto, porque a corrosão se verifica em determinados pontos, de preferencia a outros, e nem tampouco a razão de a ulcera localisar-se muitas e muitas vezes, no duodeno, cujo conteúdo é nimiamente alcalino.

Agora, a ulcera peptica se resume em um disturbio trophico, como muitos outros, de substrato nervoso, que se assestam para 0 lado da pelle e tecidos subjacentes: o mal perfurante plantar não é tão conhecido?

Surge a doutrina infecciosa da ulcera e, afinal, nem mesmo se deixam em paz as glandulas endocrinas no afan de esclarecer-se a verdadeira causa das ulceras pepticas.

A' syphilis caberia, fatalmente, a sua vez: trouxeram-na, pela mão de clinicos autorisados, e todos julgaram encontrada a incognita e abatidas as trévas que rodeavam a etio-pathogenia de tão interessantes ulceras. Mes, foi tude embalde: o mysterio continua, o cháos permanece e a escuridão ainda reina nesse capitulo da pathologia gastro-duodenal. A etiologia luetica falhou e a therapeutica cirurgica vae, mais e mais, conquistando adeptos e restituindo á caude os innumeros ulcerosos, saturados de mercurio e de arsenico.

Duas verdades clinicas: a syphilis, o agente causal por excellencia dos aneurysmas aorticos, é estranha á formação das ulceras gastro-duodenaes.

OVIDIO PIRES DE CAMPOS.

Certifico que tenho empregado com bons resultados, em minha clinica o reconstituinte VIDAN em cuja formula se associam o hypophosphito de calcio, glycerophosphato de magnesio, glycerina, kola e arsenico.

a) DR. CELESTINO BOURROUL 